\title{
From regional to local SPTHA: efficient computation of probabilistic tsunami inundation maps addressing near-field sources
}

\author{
Manuela Volpe $^{1}$, Stefano Lorito ${ }^{1}$, Jacopo Selva ${ }^{2}$, Roberto Tonini ${ }^{1}$, Fabrizio Romano ${ }^{1}$, and Beatriz Brizuela ${ }^{1}$ \\ ${ }^{1}$ Istituto Nazionale di Geofisica e Vulcanologia, Roma, Italy \\ ${ }^{2}$ Istituto Nazionale di Geofisica e Vulcanologia, Bologna, Italy
}

Correspondence: Manuela Volpe (manuela.volpe@ingv.it)

Received: 9 July 2018 - Discussion started: 18 July 2018

Revised: 8 February 2019 - Accepted: 11 February 2019 - Published: 6 March 2019

\begin{abstract}
Site-specific seismic probabilistic tsunami hazard analysis (SPTHA) is a computationally demanding task, as it requires, in principle, a huge number of high-resolution numerical simulations for producing probabilistic inundation maps. We implemented an efficient and robust methodology using a filtering procedure to reduce the number of numerical simulations needed while still allowing for a full treatment of aleatory and epistemic uncertainty. Moreover, to avoid biases in tsunami hazard assessment, we developed a strategy to identify and separately treat tsunamis generated by near-field earthquakes. Indeed, the coseismic deformation produced by local earthquakes necessarily affects tsunami intensity, depending on the scenario size, mechanism and position, as coastal uplift or subsidence tends to diminish or increase the tsunami hazard, respectively. Therefore, we proposed two parallel filtering schemes in the far- and the near-field, based on the similarity of offshore tsunamis and hazard curves and on the similarity of the coseismic fields, respectively. This becomes mandatory as offshore tsunami amplitudes can not represent a proxy for the coastal inundation in the case of near-field sources. We applied the method to an illustrative use case at the Milazzo oil refinery (Sicily, Italy). We demonstrate that a blind filtering procedure can not properly account for local sources and would lead to a nonrepresentative selection of important scenarios. For the specific sourcetarget configuration, this results in an overestimation of the tsunami hazard, which turns out to be correlated to dominant coastal uplift. Different settings could produce either the opposite or a mixed behavior along the coastline. However, we show that the effects of the coseismic deformation due to local sources can not be neglected and a suitable correction has
\end{abstract}

to be employed when assessing local-scale SPTHA, irrespective of the specific signs of coastal displacement.

\section{Introduction}

In the last 15 years a number of large earthquakes occurred worldwide, often accompanied by destructive tsunamis. In several cases, the overall size of the earthquake and/or of the tsunami was unanticipated and some surprising features were observed in terms of event scaling (e.g., source aspect ratio, tsunami height versus earthquake magnitude) or associated damage (Lay, 2015; Lorito et al., 2016); a striking example is the 2011 Tohoku earthquake and tsunami and the consequent nuclear disaster at the Fukushima Daiichi power plant (Synolakis and Kânoğlu, 2015). These events called attention to the need for a systematic reevaluation of current tsunami hazard estimates.

In the past, tsunami hazard was mostly studied through simulations of one or several scenarios, either the "worst credible" (e.g., Tinti and Armigliato, 2003; Lorito et al., 2008; Tonini et al., 2011; Løvholt et al., 2012a) or representative of different selected return periods (e.g., Løvholt et al., 2006; Harbitz et al., 2012; Brizuela et al., 2014; Gailler et al., 2015). Such an approach can be useful either as a first screening of tsunami hazard or to realize very detailed assessments for informing emergency managers of the potential impact of specific scenarios. Traditionally, the latter is often also done as a result of probabilistic hazard disaggregation (Bazzurro and Cornell, 1999). 
To account for potential variability and frequency of tsunamis, and for the inclusion of alternative models needed for quantifying epistemic uncertainty, the probabilistic treatment of a large set of potential tsunami sources is essential. Probabilistic tsunami hazard analysis (PTHA) probably began with the seminal papers of Lin and Tung (1982) and Rikitake and Aida (1988). Uncertainty quantification is one of the main goals of PTHA, and progressively more refined uncertainty treatment was achieved following the 2004 Indian Ocean tsunami (e.g., Geist and Parsons, 2006; Burbidge et al., 2008; González et al., 2009; Horspool et al., 2014; Hoechner et al., 2016; Selva et al., 2016; Davies et al., 2017; Grezio et al., 2017; Power et al., 2017). PTHA is becoming the established good practice for managing risk assessment and risk mitigation measures (Chock et al., 2016; Løvholt et al., 2017). Due to the lack of historical tsunami data, the opportunity to deal with PTHA through a computational approach, involving the probability of all of the relevant sources and the numerical modeling of the generated tsunamis, which is in the scope of all the above-mentioned papers, is emphasized by several reviews (e.g., Geist and Lynett, 2014; Grezio et al., 2017).

Nevertheless, the computational procedure for a complete evaluation of PTHA, fully exploring the natural variability of the sources, can be extremely demanding and unfeasible in some cases, particularly when inundation calculations are involved for a target site (González et al., 2009; Geist and Lynett, 2014). This is due to the very large number of numerical simulations of tsunami generation, propagation and inundation on high-resolution topobathymetric models which is, in principle, required. For example, numerous realizations of heterogeneous slip are needed and usually obtained with stochastic procedures (LeVeque et al., 2016; Sepúlveda et al., 2017). Indeed, heterogeneous earthquake slip is known to strongly influence the tsunami run-up (Geist, 2002; Løvholt et al., 2012b; Geist and Oglesby, 2014; Davies et al., 2015; Murphy et al., 2016) and not only in the near-field of the source (Li et al., 2016). Among the first attempts to quantify tsunami hazard uncertainty related to heterogeneous earthquake slip, Mueller et al. (2014) and Griffin et al. (2017) should be mentioned. Recently, Goda and De Risi (2018) proposed a multi-hazard approach including stochastic slip distributions and cascading earthquake-tsunami risk evaluation; however, they considered a limited number of tsunami scenarios without fully characterizing the epistemic uncertainties associated with the key model components. Consequently, an efficient methodology is needed to make (onshore) PTHA a computationally affordable task.

The issue has been dealt with in various ways in several studies (González et al., 2009; Thio et al., 2010; Lorito et al., 2015; Lynett et al., 2016). In particular, Lorito et al. (2015) focused on seismic PTHA (SPTHA), that is, on hazards associated with tsunamis generated by coseismic seafloor displacement. They developed a method for significantly reducing the computational cost of the assessment, using a source- filtering procedure based on a cluster analysis. This allows for the identification of a subset of important sources able to preserve the accuracy of results. Furthermore, Selva et al. (2016) proposed a general procedure for the joint and unbiased quantification of aleatory and epistemic uncertainty, including the filtering procedure of Lorito et al. (2015) while stressing the importance of source completeness.

Here, we merge the two approaches of Lorito et al. (2015) and Selva et al. (2016), fully developing a method that enables the quantification of the local-scale SPTHA, and also devoting a large effort to refining the procedure and introducing several critical improvements. On the one hand, we modified the filtering procedure to enhance its computational efficiency and to adapt it to multiple sources covering a large range of source-target distances. On the other hand, to improve the accuracy we applied a separate treatment for remote and local sources, selecting near-field scenarios on the basis of the similarity of the coseismic tsunami initial conditions. This is crucial, as near-field sources may challenge the general assumption made by Lorito et al. (2015), where, for a given source, offshore tsunami amplitude profiles are considered representative of the coastal inundation behind them, regardless of the source location with respect to the coast. This was reasonable in that particular case study, since they considered either far-field scenarios with respect to the target coast or scenarios which deformed the coast in a definite direction; that is, the coast always subsided due to subduction earthquakes on the Hellenic arc. In the presence of more complex (and realistic) local fault distribution, causing either subsidence, uplift or mixed patterns depending on the case, tsunami intensity can be unpredictably reduced or enhanced with respect to the corresponding offshore tsunami wave (Mueller et al., 2014; Griffin et al., 2017). Hence, in general, offshore tsunami profiles could be strongly misleading when coseismic deformation of the coast occurs. This may affect the tail of the hazard curves in particular (i.e., largest intensities), to which local sources significantly contribute, as also demonstrated by the disaggregation analysis in Selva et al. (2016). For all of these reasons, special treatment is needed for local sources, based on the source similarities and considering the coseismic onshore displacement, rather than the offshore tsunami wave similarity.

For illustrative purposes, we considered a target site in the central Mediterranean as a use case, the Milazzo oil refinery (Sicily, Italy) in the southern Tyrrhenian Sea. This site was previously selected within the framework of the EU project STREST (http://www.strest-eu.org/, last access: 28 February 2019) as a test case for multi-hazard stress test development for nonnuclear critical infrastructure.

It is worth noting that this paper is strictly methodological and aims to propose a computationally efficient procedure for local-scale SPTHA, rather than provide a realistic site-specific hazard assessment. In fact, for the sake of simplicity and in order to not deflect attention from the core of the method, no efforts have been dedicated to constrain and 
test the (regional) seismic rates; the local seismic sources and their geometry and dynamics, including slip distributions; or the accuracy of topobathymetric data used in tsunami simulations. Moreover, the filtering procedure has been forced to minimize the number of explicit numerical simulations, allowing a relatively large accepted error with respect to the complete initial set of sources due to the introduced approximations.

The paper is organized as follows: Sect. 2 resumes the general outline of the method for SPTHA evaluation, as proposed by Lorito et al. (2015) and Selva et al. (2016), while the innovative developments are described in Sect. 3; Sect. 4 focuses on the illustrative application; conclusive remarks are drawn in Sect. 5.

\section{A general review of the original method for SPTHA}

Using regional-scale SPTHA as input for local-scale (sitespecific) SPTHA, through the approach proposed by Lorito et al. (2015), is a task already foreseen by Selva et al. (2016) (see Fig. 1 therein). However, this possibility was neither applied nor tested in practice, since their main focus was the application for regional-scale analyses. The details of the general method have been already thoroughly described and validated in the previous studies. Here we will summarize the basic concepts.

The whole general procedure for site-specific SPTHA can be outlined in four steps: (1) the definition of earthquake scenarios and their probability, allowing, in principle, a full exploration of source aleatory uncertainty; (2) the computation, for each source, of tsunami propagation up to a given offshore isobath; (3) the selection of the relevant scenarios for a given site through a filtering procedure and the corresponding high-resolution tsunami inundation simulations; and (4) the assessment of local SPTHA with joint aleatory and epistemic uncertainty quantification by means of ensemble modeling, including modeling alternatives that were eventually implemented during steps (1)-(3).

In step (1), all the modeled earthquakes must be defined for different seismic regions, which are assumed to be independent of each other. The earthquake parameters and their logically ordered conditional probabilities are treated by means of an event tree technique. We emphasize that the common assumption that tsunami hazard is dominated at all timescales by subduction zone earthquakes is not used: nonsubduction faults, unknown offshore faults, and diffuse seismicity around major known and well mapped structures are all taken into account. This strategy attempts to prevent biases in the hazard due to the incompleteness of the source model (Basili et al., 2013; Selva et al., 2016). The seismicity related to the main and better-known fault interfaces is treated separately to the rest of the crustal and diffuse seismicity. A similar approach has been used in the recent TSUMAPS-NEAM project (http://www.tsumaps-neam.eu/, last access: 28 February 2019), which provided the first SPTHA model for the northeastern Atlantic, Mediterranean and connected seas (NEAM) region.

In step (2), for each scenario retrieved from step (1) the corresponding tsunami generation and propagation is numerically modeled, and the pattern of offshore tsunami height above the sea level $\left(H_{\max }\right)$ is evaluated at a set of points along the $50 \mathrm{~m}$ isobath in front of the target area. To provide the input for Lorito et al. (2015), these points may be limited to a profile in front of the site. The length of this control profile must be tuned depending on the morphology and the extension of the target coast: a compromise has to be reached, as too few points could make the profile not representative enough, while too many points could downgrade the performance of the subsequent filtering procedure (Lorito et al., 2015). Actually, the optimal length is the shortest one that makes the offshore hazard curves stable with respect to the source selection, and a further increase in length would increase the computational effort without significantly altering the results.

In step (3), using the offshore $H_{\max }$ profiles calculated during step (2), a filtering procedure is implemented to select a subset of relevant sources, based on the similarity of the associated tsunami intensity and not on the similarity or spatial proximity of the sources themselves. The selected sources, each of them representative of a cluster of sources producing comparable tsunamis offshore of the target area, are then used for explicit inundation modeling on high-resolution topobathymetric grids. This approach allows for a consistent and significant reduction of the computational cost while preserving the accuracy. However, Lorito et al. (2015) considered a limited set of sources. The extension to a much larger set of potential sources requires some modifications to the method that, along with several other improvements, are proposed in this study, as reported in Sect. 3.

Incidentally, we note that other wave properties, such as period or polarity, could be relevant in the framework of the cluster analysis. However, Lorito et al. (2015) briefly discussed this issue, also with respect to the length of the control profile, as discussed above. Nevertheless, this is a point probably deserving further investigation, considering that Satake et al. (2013) showed how inundation from the Tohoku 2011 tsunami was variably controlled by long-period offshore tsunami components on flat coastal plains and shorter-period peaks in steep coastal areas. Indeed, Gusman et al. (2014) used two cycles of a tsunami for identifying similar waves. Conversely, since, as described in the next section, offshore wave comparison is not used anymore in the near-field, this issue will not apply for local sources.

In step (4), local SPTHA is quantified. The inundation maps for each representative scenario from step (3) are aggregated according to the probabilities provided during step (1), assigning the total probability of a cluster to the representative scenario. Aleatory and epistemic uncertainty are simultaneously quan- 
tified by means of an ensemble-modeling approach (Marzocchi et al., 2015; Selva et al., 2016) over alternative implementations of the previous steps. In practice, steps (1) to (3) can be iterated for each alternative model, and these alternatives can be weighted according to their credibility and the possible correlation among the models. The results are finally integrated through ensemble modeling into a single model which expresses both aleatory and epistemic uncertainty.

\section{Improvements in the filtering procedure}

The described method has been tested by both Selva et al. (2016) and Lorito et al. (2015). However, Lorito et al. (2015) focused on the filtering procedure of step (3), adopting a simplified configuration for the source variability, in which sources were allowed only within the Hellenic arc; that is, an area that is a source area too small to represent the full earthquake aleatory variability. On the other hand, Selva et al. (2016) applied the approach to a regional study that extended to the Ionian Sea in the central Mediterranean Sea. The quantification of the local hazard is instead discussed only in theory, without proposing any application.

The original method of Lorito et al. (2015) adopted a twostage procedure.

In the first stage, scenarios giving a negligible contribution to $H_{\text {max }}$ offshore of the target area were removed, assuming they would lead to negligible inundation. Hereafter, we call this stage "Filter H".

As a second filtering stage, a hierarchical cluster analysis (HCA) was carried out, separately for each earthquake magnitude class included in the seismicity model, under the assumption that sources producing similar offshore $H_{\max }$ along the control profile will also produce similar inundation patterns. The distance $(\mathrm{d})$ between two $H_{\max }$ patterns from two different scenarios, $u$ and $v$, was measured by a cost function previously used to compare tsunami waveforms in source inversion studies (e.g., Lorito et al., 2010; Romano et al., 2010) and modified by Lorito et al. (2015) as follows:

$d\left(H_{\max }^{u}, H_{\max }^{v}\right)=\left[1-\frac{2 \sum_{x} H_{\max }^{u, x} H_{\max }^{v, x}}{\sum_{x}\left(H_{\max }^{u, x}\right)^{2}+\left(H_{\max }^{v, x}\right)^{2}}\right]$,

where $x$ runs over the control points of the $50 \mathrm{~m}$ isobath. For each cluster, the scenario closer to the centroid was selected as the reference scenario, with an associated probability corresponding to the probability of occurrence of the entire cluster. The optimal number of clusters (i.e., the "stopping criterion") was assessed by analyzing the variance within each cluster (hereafter, "intra-cluster") as a function of the number of clusters and selecting the largest value still producing significant changes, according to the so-called Beale test (Lorito et al., 2015, and references therein).
We implemented a different strategy to further reduce the number of explicit tsunami simulations and introduced a separate treatment for local and remote sources. In particular, the source scenario filtering procedure was revised to improve both the computational efficiency and accuracy, allowing for a full scalability to the source variability of typical SPTHA (millions of scenarios located all over an entire basin). A schematic diagram of the new procedure is sketched in Fig. 1, with (right, step 3b) or without (left, step 3a) the separation between near- and far-field.

We still kept Filter $\mathrm{H}$ but also adopted an additional filter on the occurrence probability (hereafter, "Filter P"; see Fig. 1), discarding scenarios whose cumulative mean annual rate (mean of the model epistemic uncertainty) is below a fixed threshold. Filter P works as follows. Scenarios are sorted according to their mean annual rate and the less frequent are removed until the cumulated rate reaches the selected threshold. This allows for a further reduction of the number of required numerical simulations. On the other hand, this operation introduces a controlled downward bias to the estimated hazard, whose upper limit corresponds (on average) to the probability threshold of Filter P. This threshold can be set at a negligible level in the framework of the overall analysis and/or with respect to other uncertainties. In addition, it can be empirically checked as to what extent this affects the results by analyzing the offshore hazard curves at the control points. This check was quantitatively done by computing the maximum deviation between the mean hazard curves at each control point before and after Filter $\mathrm{P}$ was applied. We also notice that, as reported in Fig. 1, Filter P was always applied after Filter $\mathrm{H}$ due to strategic reasons of optimization; in fact, the cumulated rate curve is lowered by the removal of small events (i.e., producing small $H_{\text {max }}$ ), which typically feature high-occurrence probability. As a consequence, a greater number of scenarios can be removed before reaching the imposed threshold, making Filter $\mathrm{P}$ more efficient.

Additionally, the cluster analysis stage was modified. Firstly, we used a different algorithm, as the large number of source scenarios due to a realistic fault variability distribution in some cases can make the HCA a computationally unaffordable task. We implemented the more efficient $k$-medoids-clustering procedure (Kaufman and Rousseeuw, 2009; Park and Jun, 2009) based on the minimization of the sum of the intra-cluster distances, that is, the distances between each element of a cluster and the cluster centroid. Strong constraints on the distances result in a more accurate partitioning in terms of similarity among the elements of each cluster but lead to a great number of clusters. Instead, larger ranges of acceptability increase the efficiency of the algorithm, in terms of number of resulting clusters, to the detriment of the accuracy. The cluster analysis was performed separately for groups of scenarios with similar mean $<H_{\max }>$ along the profile instead of grouping scenarios by earthquake magnitude class. This makes the partition- 


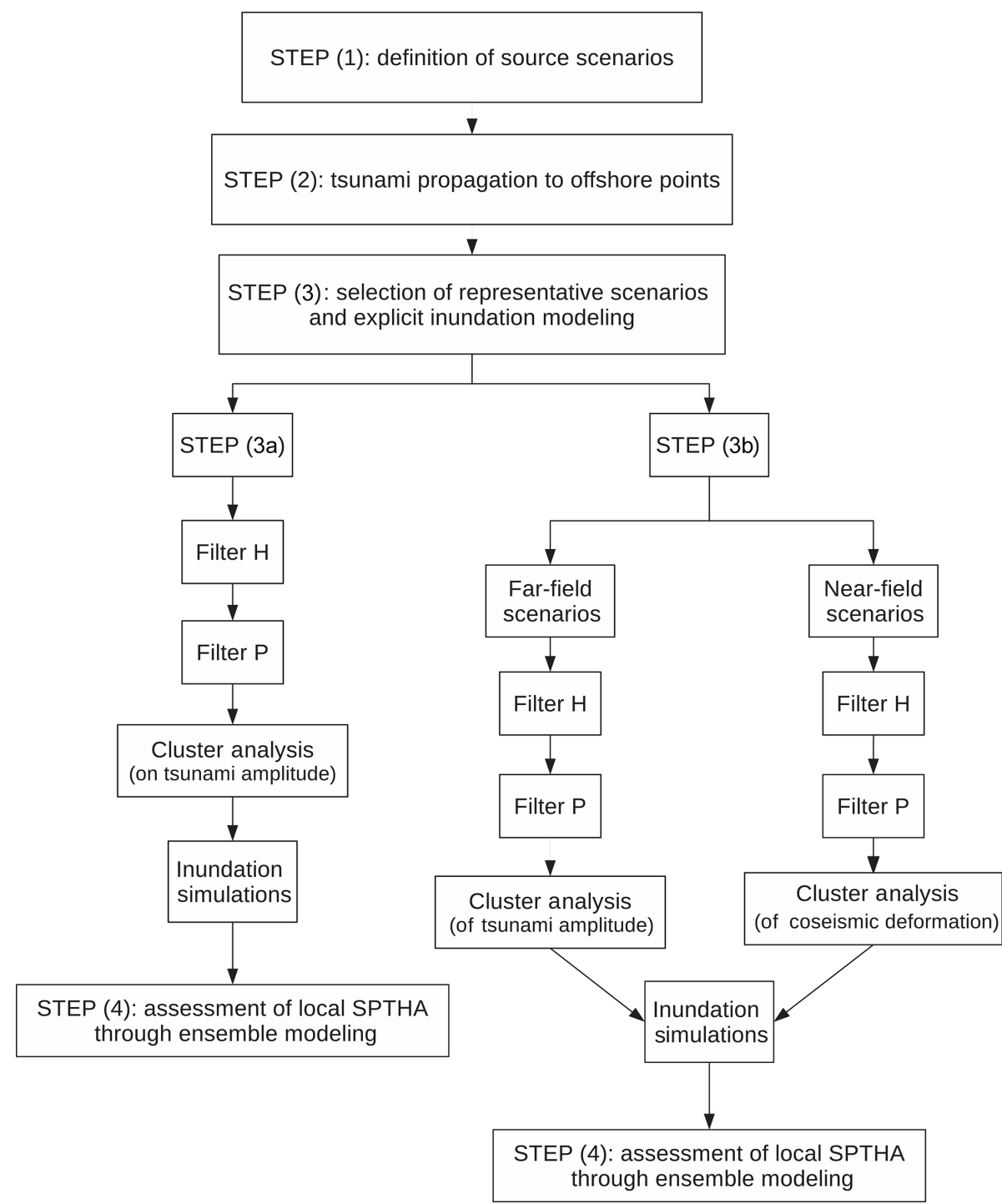

Figure 1. Schematic diagram of the computational procedure for evaluating site-specific SPTHA, with special attention paid to step (3) (see text).

ing more efficient, as the earthquake magnitude can not be considered the only parameter controlling the tsunami intensity, as it was for the limited set of sources adopted by Lorito et al. (2015). The cluster distance was measured by Eq. (1), but we updated the stopping criterion, which is now related to the maximum allowed intra-cluster variance, rather than being a blind optimization of the number of clusters. More specifically, to control the dispersion within each cluster, we set a threshold for the maximum allowed squared Euclidean distance. This threshold was empirically fixed by comparing the offshore hazard curves before and after the analysis and assuming an acceptable range of variability, analogous to the approach used for Filter P.

Finally, and probably most importantly, in order to deal with the contribution from local sources properly, we imple- mented two independent filtering schemes for distant and local sources. Indeed, special treatment for near-field sources is needed, as the coseismic deformation can modify the actual local tsunami intensity at the nearby coast, due to coastal uplift or subsidence. As a consequence, the offshore tsunami amplitude profiles generated by such events may fail to be representative of the coastal inundation, and separate modeling is required using the coseismic deformation as the metric for source proximity in the cluster analysis (details below). This issue was somehow hidden in Lorito et al. (2015), due to the relatively small aleatory variability they considered being the source either in the far- or near-field, depending on the target site, but never mixed together. In addition, this separation may favor some refinement of the near-field source discretization and modeling, such as a denser sampling of geo- 
metrical parameters and/or the introduction of heterogeneous slip distributions.

For testing the proposed method, we replaced step (3) either with step (3a) or step (3b), as displayed in Fig. 1. The workflow of step (3a) is almost equivalent to the original procedure of Lorito et al. (2015) improved by the aforementioned changes related to the algorithm optimization, whereas the separate treatment of near- and far-field sources is included in step (3b). Step (3a) is then used in this study as a term of comparison for the new scheme.

In step (3a), three sequential tasks were performed, namely Filter H, Filter P and the cluster analysis based on the offshore tsunami amplitudes.

In step (3b), local and distant sources were firstly detected based on the coseismic deformation produced by the earthquake near and on the target coast. The procedure was then split into two parallel paths, which need to be merged at the end when evaluating SPTHA (Fig. 1). As far as the far-field scenarios are concerned, the same workflow as step (3a) was followed. Near-field scenarios, which, in principle, should be individually modeled, were also filtered in order to reduce the number of explicit inundation simulations: this of course introduces a new approximation, which, however, is better than aggregating local and remote scenarios on the basis of the offshore tsunami amplitudes. Filter $\mathrm{H}$ was applied as well, but a smaller threshold value was chosen: a more conservative approach is indeed recommended at this stage, as offshore values could be strongly misleading when significant coastal coseismic deformation occurs. Then Filter $\mathrm{P}$ was employed, and finally a cluster analysis was performed by comparing the coseismic deformations instead of the (unrepresentative) offshore tsunami amplitudes. For each local source, the vertical component of the coseismic displacement was calculated on a 2-D grid centered around the fault, which has a size equal to 3 times the fault length. Then the cluster analysis was carried out, separately for each magnitude, by comparing the coseismic fields point to point within the grid. In this case, the cluster analysis is based on the squared Euclidean distance instead of the cost function; the stopping criterion is also evaluated through the Euclidean distance, since the coseismic field can take both positive and negative values.

The selected earthquake scenarios from step (3a) or from the two branches (near- and far-field) of step (3b) were then used for high-resolution inundation simulations and combined together in step (4) when evaluating SPTHA. A practical example of the whole procedure is illustrated in the next section.

\section{The Milazzo oil refinery (Sicily, Italy) use case}

The described procedure was applied to a test site, Milazzo, located on the northeastern coast of Sicily, Italy, within the Mediterranean Sea. The site houses an oil refinery, one of the nonnuclear critical infrastructures selected as a case study in the framework of the EU project STREST (http://www. strest-eu.org/, last access: 28 February 2019).

Due to the illustrative purposes of the present work, some strong assumptions were imposed during the filtering procedure to drastically reduce the number of required explicit numerical simulations. The tuning of the filtering thresholds is not the objective of the present work; in fact, this application is aimed at highlighting that inaccurate (biased) evaluation of site-specific tsunami hazard would be obtained if scenarios located in the near-field of the target area are not properly taken into account, irrespective of the completeness and consequent complexity of the hazard assessment. However, more sanity and sensitivity tests would be mandatory for a finer tuning of thresholds and modeling in the case of a real application. For example, the modeling of near-field scenarios is expected to be dependent on the source parameters, especially concerning the heterogeneous slip distribution on the fault plane (e.g., Geist and Oglesby, 2014), which was not included here. Hence, the computational effort of a real assessment, including a wider source variability and more conservative thresholds, is expected to be more complicated and computationally demanding than this case study.

Regarding step (1), the adopted seismicity model was previously developed in the framework of the EU project ASTARTE (http://www.astarte-project.eu, last access: 28 February 2019). This model extends the method applied to the Ionian Sea in Selva et al. (2016) to the entire Mediterranean Sea, including the subduction interfaces of the Calabrian and Hellenic arcs as well as crustal seismicity in the whole basin (see Fig. 2a). In subduction zones, events of different magnitudes and positions over the whole interface are allowed, disregarding the geometry uncertainty of the slab; conversely, crustal seismicity is allowed to occur with any meaningful geometry and mechanism in the whole seismogenic volume at different magnitudes and depths. The complete set of sources retrieved from step (1) contains about 40 million elements, among which 1701341 scenarios actually affect the target site $\left(H_{\max }>0.05 \mathrm{~m}\right.$ offshore of Milazzo). Although relatively simplified, the source model also includes epistemic uncertainties of many source parameters such as the seismic rates, the shape of the magnitudefrequency distribution and the seismogenic depth interval for the two subduction zones.

Tsunami amplitudes, step (2), were computed on a control profile made of 11 points offshore of the Milazzo target area (on the $50 \mathrm{~m}$ isobath), as reported in Fig. 2a. To save computational time, scenarios from step (1) were not individually simulated but were obtained by a linear combination of precalculated tsunami waveforms produced by Gaussian-shaped unitary sources (Molinari et al., 2016). The Gaussian propagation was modeled by the Tsunami-HySEA code, a nonlinear hydrostatic shallow-water multi-GPU code based on a mixed finite-difference-finite-volume method (de la Asunción et al., 2013; Macías et al., 2016, 2017). 

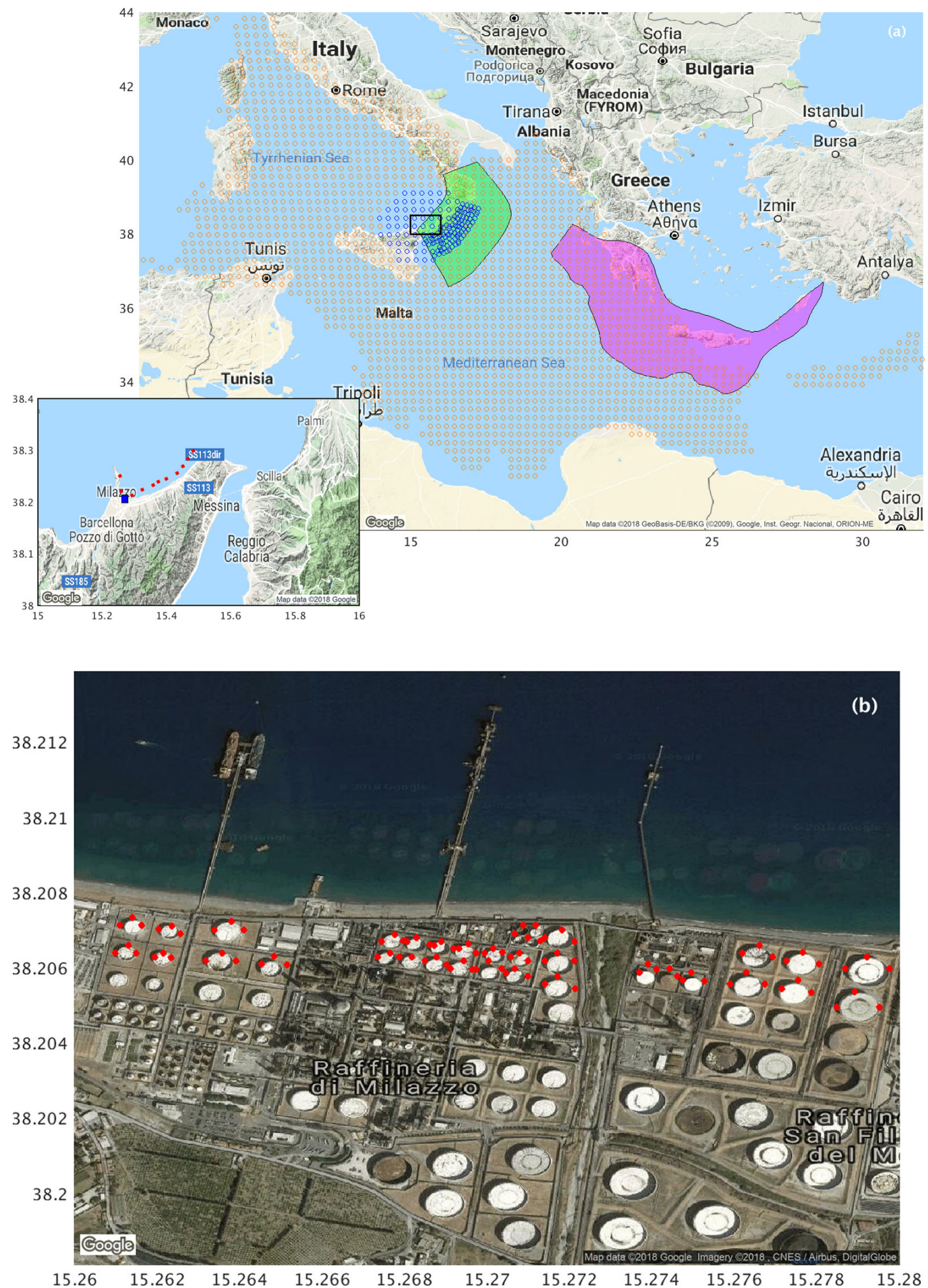

Figure 2. (a) Map of the whole simulation domain used for the application at the target site Milazzo (Sicily, Italy). The orange circles are the geometrical centers of the crustal faults affecting the target site, while the magenta and the green regions are the slab models of the Hellenic and Calabrian arcs, respectively. Blue circles are the geometrical centers of the near-field sources, as detected in step ( $3 \mathrm{~b}$ ) (see text). The inset highlights the offshore points along the $50 \mathrm{~m}$ isobath (red points). The blue square within the inset is the area displayed in the bottom panel. (b) Zoom of the Milazzo oil refinery, with the position of the 95 points at the edges of the storage tanks (red points). 
Step (3) was addressed by independently performing the two branches (3a) and (3b), as discussed in the previous section, and then comparing results to assess the importance of the separate treatment of the near-field sources.

In step (3a), thresholds were fixed at $1 \mathrm{~m}$ for Filter $\mathrm{H}$ and $10^{-5} \mathrm{yr}^{-1}$ for Filter P. This resulted in discarding scenarios with an individual mean annual rate below $\sim 10^{-9} \mathrm{yr}^{-1}$, causing a maximum bias in the offshore mean hazard curves of about $10 \%$ in the considered range of tsunami intensities, with respect to the curves obtained without Filter P. At the end of the filtering procedure, imposing a threshold equal to 0.2 on the intra-cluster variance, we obtained 776 clusters, each associated with a representative scenario. That is, we had a reduction above $99 \%$. Figure S1 in the Supplement shows the comparison among the mean offshore hazard curves at the 11 control points, as well as among some quantiles of the epistemic uncertainty, for the filtered and original set of scenarios.

It is worth stressing that the efficiency of the filters is artificially enhanced here by the imposed high thresholds, especially as far as Filter $\mathrm{H}$ is concerned. While $1 \mathrm{~m}$ is not an acceptable value in the case of a real hazard assessment, it is suitable for illustrative purposes. In any case, this filter, independently of the chosen threshold, is not expected to affect subsequent steps of the procedure for tsunami intensities above the threshold. Conversely, we performed a sensitivity analysis on the threshold imposed on the intra-cluster variance for the cluster analysis; Fig. S2 shows the percentage differences between the offshore hazard curves computed from the complete initial set of sources and the filtered set. The red box corresponds to the chosen threshold value (0.2): it appears evident that a smaller value would have allowed a stronger constraint on the error introduced by the cluster analysis while considerably increasing the number of resulting clusters. Vice versa, higher thresholds produce a smaller number of clusters but fail in reproducing the hazard (an error of up to $40 \%$ ). In the case of a real hazard assessment, this analysis would help in choosing an optimal threshold.

In step (3b), we considered as local scenarios, requiring separate processing, sources that generate a coseismic vertical displacement greater than or equal to $0.5 \mathrm{~m}$ on a set of near-field points; that is, the 11 control points on the $50 \mathrm{~m}$ isobath plus 95 inland points strategically located at the edges of the refinery storage tanks, as shown in Fig. $2 b$. We found 4721 scenarios in the near-field (see Fig. 2a). Afterwards, for both branches we applied Filters $\mathrm{H}$ and $\mathrm{P}$ as well, using the following thresholds: for far-field scenarios, Filter $\mathrm{H}=1 \mathrm{~m}$ and Filter $\mathrm{P}=5 \times 10^{-6} \mathrm{yr}^{-1}$; for near-field scenarios, Filter $\mathrm{H}=0.1 \mathrm{~m}$, according to the more conservative approach described in the previous section, and Filter $\mathrm{P}=5 \times 10^{-6} \mathrm{yr}^{-1}$. Note that the Filter $\mathrm{P}$ threshold was set to half of the value used in step (3a), in order to keep a total maximum theoretical bias on the hazard curves at $10^{-5} \mathrm{yr}^{-1}$, as in step (3a), considering that Filter P is separately applied both to far- and near-field scenarios. Then the cluster analysis was carried out on the tsunami amplitudes for far-field scenarios (using a threshold equal to 0.2 on the intra-cluster variance) and on the coseismic deformation for near-field scenarios (using a $10 \%$ threshold for the intra-cluster variance). We obtained 634 and 520 clusters for remote and local sources, respectively. Thus, the total number of representative scenarios (1154) to be explicitly modeled corresponds to a reduction of above $99 \%$ of the initial set of sources.

Inundation simulations from step (3) were carried out again with the Tsunami-HySEA code, exploiting the nested grid algorithm. We used four-level nested bathymetric grids with a refinement ratio equal to 4 and increasing resolution from $0.4 \operatorname{arcmin}(\sim 740 \mathrm{~m})$, to $0.1 \mathrm{arcmin}$ ( $185 \mathrm{~m})$, to $0.025 \mathrm{arcmin}(\sim 46 \mathrm{~m})$ and to $0.00625 \mathrm{arcmin}$ $(\sim 11 \mathrm{~m})$. The largest grid was obtained by resampling the SRTM15+ bathymetric model (http://topex.ucsd. edu/WWW_html/srtm30_plus.html, last access: 28 February 2019). The three finest grids were produced by interpolation from TINITALY (inland; Tarquini et al., 2007, 2012) and EMODNET (offshore; http://www.emodnet-bathymetry.eu/, last access: 28 February 2019) and working on grids of 0.00625 arcmin that were resampled at 0.1 and 0.025 arcmin. A picture of the telescopic nested grids is provided in Fig. S3. The initial conditions were differently provided for subduction and crustal seismicity. The subduction scenarios were simulated by modeling the slab as a 3-D triangular mesh honoring the interface profile and using unitary Okada sources associated with each element of the mesh (i.e., to each triangle) as Green's functions (Okada, 1985; Meade, 2007). For crustal events, the initial sea level elevation was obtained by modeling the dislocation on rectangular faults according to the Okada model. A Kajiura-like filter for the sea bottomwater surface transfer of the dislocation was also applied (Kajiura, 1963). For each simulation an overall length of $8 \mathrm{~h}$ was fixed. The results were stored as maximum wave height $\left(H_{\max }, \mathrm{m}\right)$ and maximum momentum flux $\left(\mathrm{MF}_{\max }, \mathrm{m}^{3} \mathrm{~s}^{-2}\right)$ at each point of the inner (highest-resolution) grid.

During step (4), SPTHA was evaluated in parallel using results both from steps (3a) and (3b) in order to compare the outcomes of the two different workflows and estimate the impact of the special treatment of near-field sources on the sitespecific hazard assessment. Note that alternative models for the epistemic uncertainty were only considered at step (1), that is, only as far as the probabilistic earthquake model is concerned, since the Selva et al. (2016) model was used.

Figures 3 to 5 compare the results from steps (3a) and (3b) in terms of mean hazard curves and inundation (both probability and hazard) maps for $H_{\max }$. At first glance, differences are appreciable in both the curves and the maps. It is worth noting that results at $H_{\max }<1 \mathrm{~m}$ can be (negatively) biased since they are depleted from the scenarios removed by Filter H, both in step (3a), as is clearly shown in Fig. S1, and in the far-field branch of step (3b). Curves and maps will be described in more detail below. 

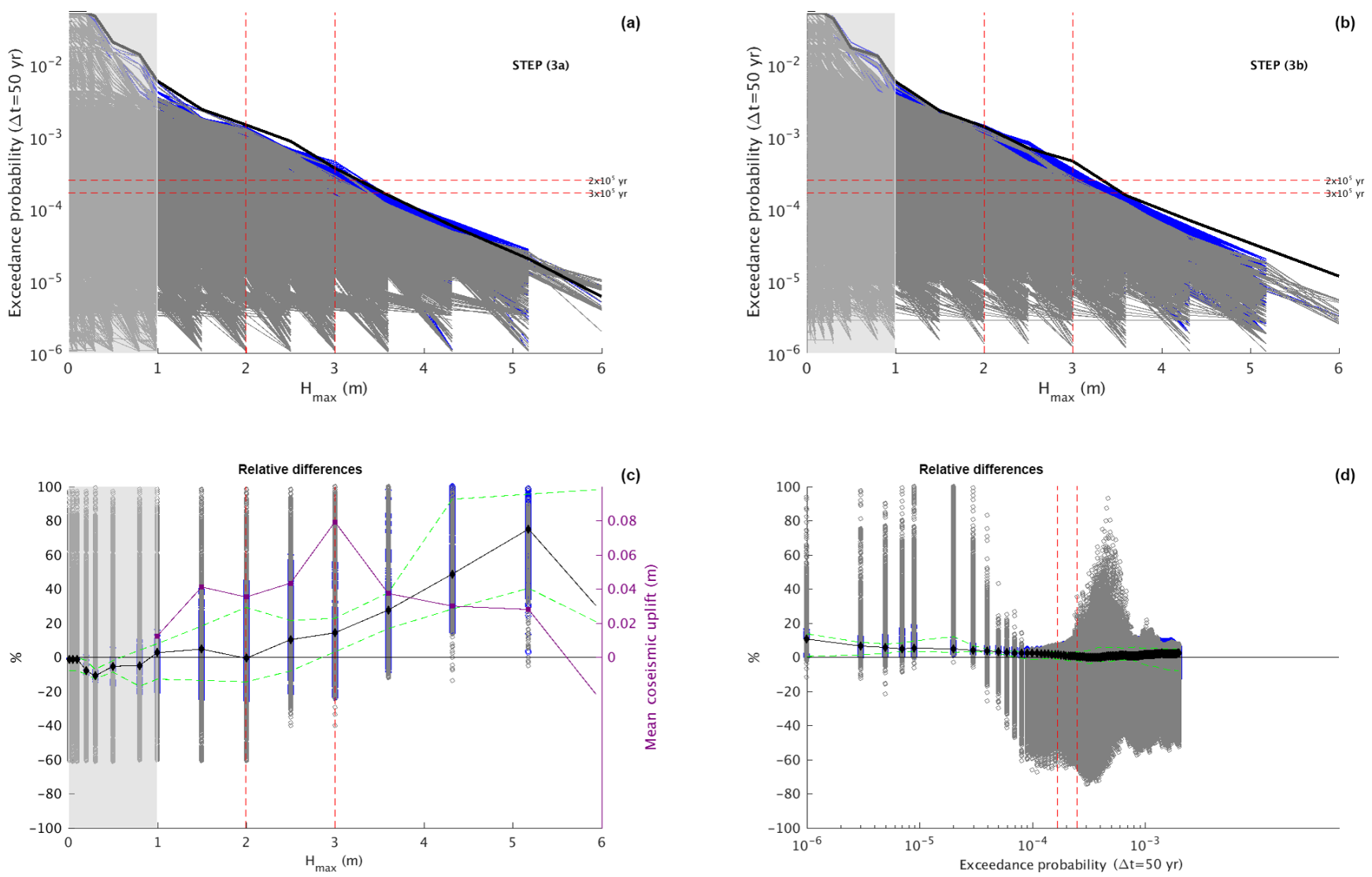

Figure 3. (a) Mean hazard curves for $H_{\max }$ at all points within the highest-resolution grid, as obtained from step (3a) of the SPTHA procedure (see text and Fig. 1). Gray and blue colors refer to inland and offshore points, respectively. The bold black line represents the envelope of the curves from step (3b). Red dashed lines represent the values used to obtain probability (Fig. 4) and hazard (Fig. 5) inundation maps. (b) Same as (a) but using step (3b). The bold black line is the envelope of the curves from step (3a). (c) Relative differences in terms of exceedance probability (over 50 years) as a function of $H_{\max }$, computed as [(3a) - (3b)]/(3b). The black line is the median of the point distribution; the green dashed lines correspond to the 16th and 84th percentile. The mean uplift (MU) on a random point along the coastline (see text) is also superimposed (purple line). (d) Same as (c) but in terms of $H_{\max }$ as a function of the exceedance probability (over 50 years).

The hazard curves in Fig. 3a and $\mathrm{b}$ show the mean (mean of the model epistemic uncertainty) exceedance probability over 50 years for $H_{\max }$ (evaluated assuming a Poisson process, as in Selva et al., 2016), plotted for each point of the finest-resolution grid. Panel (c) of the same figure displays the one-by-one relative differences in terms of exceedance probability (over 50 years), as a function of $H_{\max }$, between the step (3a) and (3b) curves at each grid point. For values of $H_{\max }$ greater than $1 \mathrm{~m}$, the relative differences are systematically positive, meaning that without the correction for nearfield scenarios, step (3a), the tsunami hazard would be overestimated. In Fig. S4 a sample of curves at a few inland points (one every thousand points) is displayed for a direct curveby-curve comparison between the two approaches. This confirms that, overall, the uncorrected approach leads to hazard overestimation. We may argue that this is true in the case of this specific setting, as a lower "corrected" hazard means that the predominant effect of local sources contributing to a specific point on the hazard curve is due to the coastal uplift, which in turn decreases the tsunami hazard. For example, a cluster may mix far- and near-field sources, which could be misrepresented by one far-field source selected as cluster representative. In our case, there might be a prevalence of clusters causing coastal uplift from the near-field sources. The situation may be the opposite for a different source-target configuration; that is, coastal subsidence could be predominant, causing an hazard increase, which without correction could be underestimated. To confirm our inference we performed some further testing. For each hazard intensity, and only for the mean model of the epistemic uncertainty, we computed the coseismic coastal displacement in the inner grid, averaged both over all of the scenarios and over all of the coastal points (purple line in Fig. 3c). This quantity can be regarded as the mean uplift (MU) on a random point on the coastline. Scenarios of different types contribute to MU, both in far-field scenarios, which do not alter the coastline, and in near-field scenarios, which may include a mixture of sources producing both coastal subsidence and uplift. 

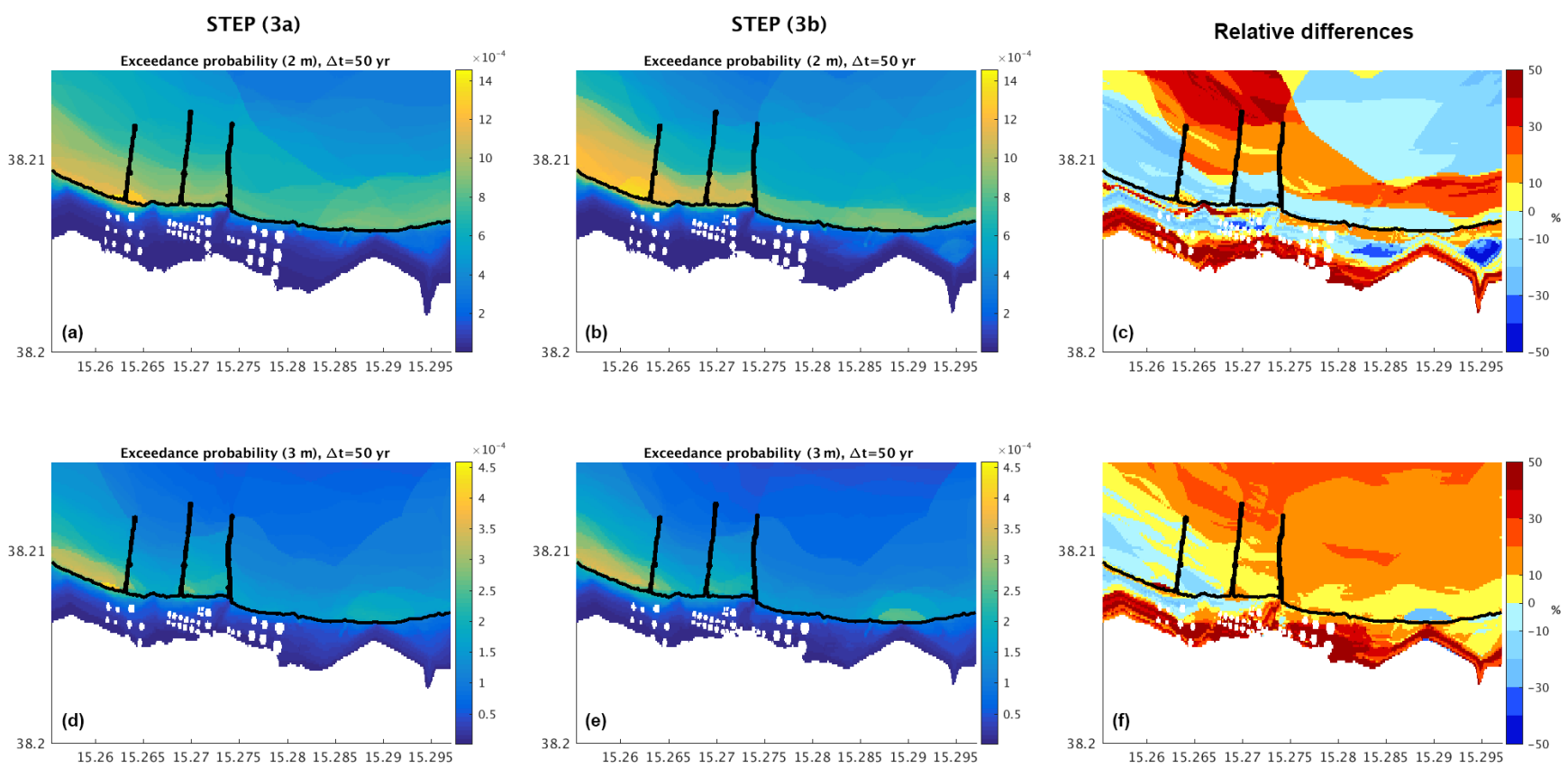

Figure 4. Probability maps (inner grid; see text) for $H_{\max }$ derived from the hazard curves in Fig. 3 at two different thresholds ( 2 and 3 m) for steps (3a) and (3b) and relative differences, which are computed as follows: $[(3 a)-(3 b)] /(3 b)$.
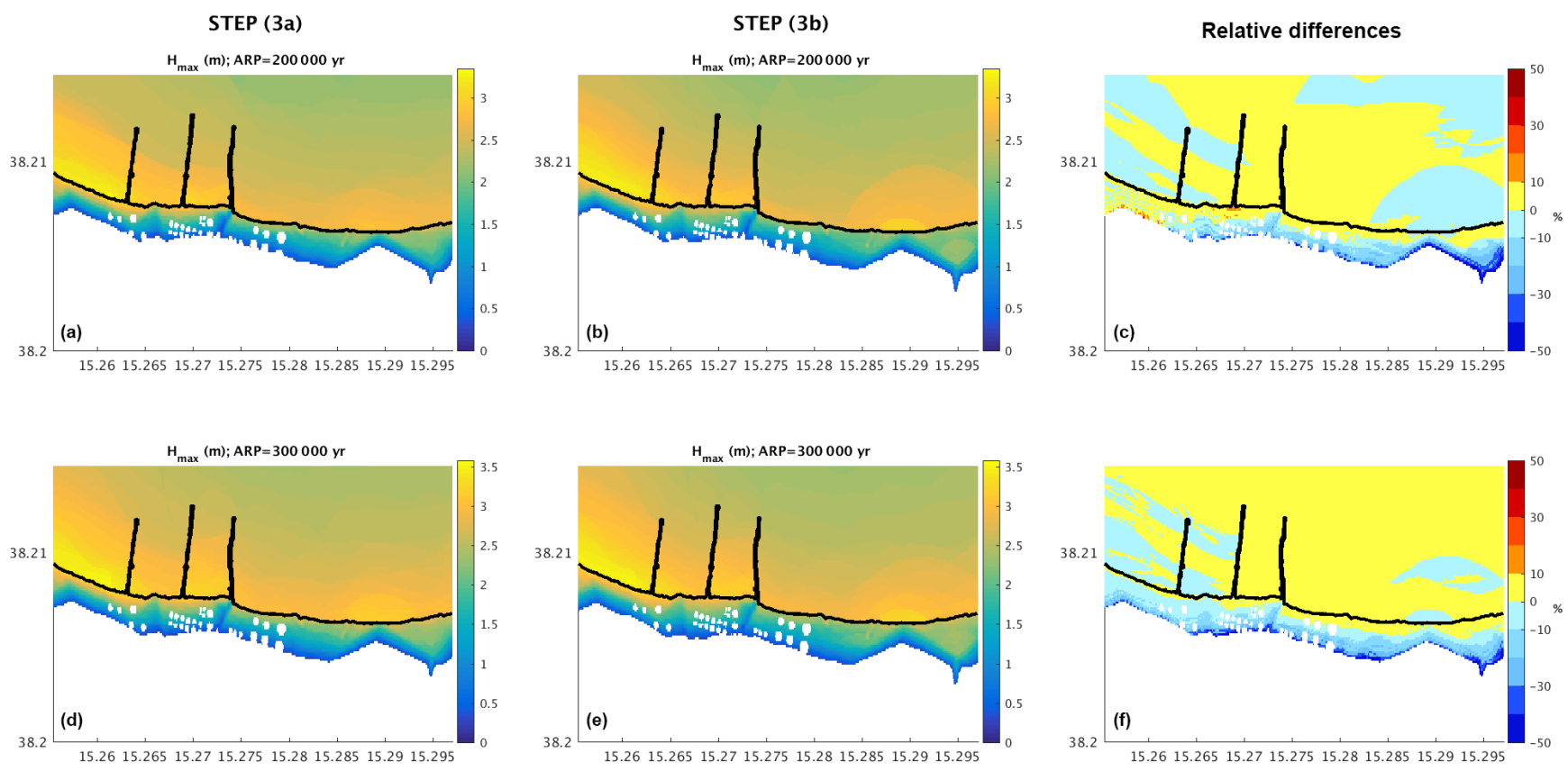

Figure 5. Hazard maps (inner grid; see text) for $H_{\max }$ derived from the hazard curves in Fig. 3 at two different ARPs $\left(2 \times 10^{5}\right.$ yr, $3 \times 10^{5}$ yr $)$ for steps (3a) and (3b) and relative differences, which are computed as follows: $[(3 a)-(3 b)] /(3 b)$.

In more detail, we firstly performed a weighted average of the coseismic displacements from each cluster centroid for each $H_{\max }$ with weights equal to the annual probability of the individual earthquakes. These probabilities are set to zero if the earthquake does not deform the coastline (i.e., for farfield sources) or if the generated tsunami does not exceed the given $H_{\max }$ value (i.e., that scenario does not contribute to the hazard at that point). The weighted average is then normalized to the total probability of the near- and far-field sources contributing to the tsunami hazard for that threshold. The resulting MU on each coastal point is plotted for different values of $H_{\max } \geq 1 \mathrm{~m}$ in Fig. S5 (blue lines). The 
displacements due to the single cluster representatives are also shown (red lines). We note that although single scenarios produce both positive and negative coastal displacements, the predominant contribution is unveiled by the sum of the different clusters, which is definitely positive. Additionally, for higher intensities the contributing scenarios (decreasing in number, as expected) generate displacements which are smaller and smaller, as important uplift would significantly limit tsunami inundation. Finally, we further averaged the resulting values along the coastline, obtaining the purple curve in Fig. 3c. We notice that the absolute MU value in meters turns out to be rather small as a result of the average over sources that cause either uplift or subsidence, or no coastal displacement at all. Regardless, the positive values obtained for $H_{\max }>1 \mathrm{~m}$ indicate that the uplift of the coast is prevailing, consistent with the positive percentage differences retrieved between the two approaches. Very little difference is retrieved between the "corrected" and the "uncorrected" filtering procedures for smaller values of $H_{\max }$, that is, below the Filter $\mathrm{H}$ threshold.

Finally, in Fig. 3d the relative differences are also shown in terms of $H_{\max }$ as a function of exceedance probability (over 50 years). In the low-probability region, typically corresponding to high $H_{\max }$, the overestimation by step (3a) is confirmed; conversely, for exceedance probability greater than $\sim 10^{-4}$, which is likely to correspond to small $H_{\max }$, a greater dispersion with both positive and negative values is observed.

Probability and hazard inundation maps can be achieved by vertically and horizontally cutting the hazard curves at chosen fixed values, in order to give a geographical representation of results. As each hazard curve corresponds to a grid point, the probability maps are obtained by plotting all the probability values for a fixed value of the intensity metric on a map. Instead, in the hazard maps the intensity values are plotted for a fixed exceedance probability, corresponding to a given average return period (ARP). In Fig. 4 we computed the exceedance probability maps for $H_{\max }=2 \mathrm{~m}$ and $H_{\max }=3 \mathrm{~m}$, while in Fig. 5 we extracted the hazard maps for ARP $=2 \times 10^{5} \mathrm{yr}$ and $\mathrm{ARP}=3 \times 10^{5} \mathrm{yr}$ (corresponding to an exceedance probability over 50 years equal to 2.5 and $1.7 \times 10^{-4}$, respectively).

For the selected values, the maps confirm what we already discussed about the curves: mostly positive relative differences both inland and offshore are inferred from the probability maps, as shown in Fig. $4 \mathrm{c}$ and $\mathrm{f}$, which are even larger than $50 \%$; these differences are positive at a larger number of points for the higher intensity, consistent with Fig. 3c. We recall that positive differences mean that the "uncorrected" procedure, step (3a), actually overestimates the tsunami hazard at the target site. Negative inland values are also observed for $H_{\max }=2 \mathrm{~m}$, but they occur for very low-probability values and should not be further investigated. We also notice that the area inundated with a non-negligible probability decreases in size when increasing the $H_{\max }$ value as expected.
In the hazard maps (Fig. 5) a complex pattern is revealed when inspecting the relative differences (panels $\mathrm{c}$ and $\mathrm{f}$ ), as both positive and negative values are retrieved. This happens because the analyzed ARPs lie in the low-intensity range. The inundated area, opposite to the previous case, is consistently more extended for larger ARPs.

Further details about the comparison can be found by analyzing the curves and the maps for $\mathrm{MF}_{\max }$ reported in Figs. S6 to S8. We merely note that, when the correction for near-field is taken into account, the inundation maps highlight an enhanced current vorticity near the docks (Figs. S7b, e and S8b, e), which is a known effect due to the flow separation at the tip of a breakwater (Borrero et al., 2015). As the probability and hazard maps aggregate several different sources, the hazard integral may tend to average and cancel out different source effects while enhancing local propagation features. The presence of such persistent physically meaningful effects only in the maps retrieved using step (3b) confirms the importance of the special treatment. In other words, the blind cluster analysis, step (3a), exclusively based on the offshore tsunami amplitudes, likely produced a nonrepresentative selection of the important scenarios, as it could aggregate or even remove important local scenarios.

\section{Conclusions}

We proposed a computationally efficient approach to achieve robust assessment of site-specific SPTHA, developing an improved version of the method of Lorito et al. (2015) and Selva et al. (2016).

The procedure is based on four steps, which can be summarized as follows: (1) the definition of the set of earthquake scenarios and their mean annual rates, exploring the source aleatory uncertainty; (2) the computation of tsunami propagation up to an offshore isobath; (3) the implementation of a filtering procedure to select relevant scenarios for the target site, which are then explicitly modeled; and (4) the assessment of local SPTHA through an ensemble-modeling approach, to jointly quantify aleatory and epistemic uncertainty, stemming from alternative models for steps (1)-(3).

In the present work we focused on step (3), modifying the filtering procedure to enhance the computational efficiency and introducing a separate treatment for sources located in the near-field, to take into account the effect of the coseismic deformation on the tsunami intensity. To achieve this aim we implemented a new procedure including a correction for near-field scenarios and some numerical improvements. We benchmarked the new approach against an algorithm that is essentially equivalent to the original method of Lorito et al. (2015). The correction is crucial as the latter is based on the assumption that offshore tsunami profiles are representative of the inundation at the nearby coast, which might be true if a coseismic deformation of the coast is not involved; otherwise, seafloor uplift or subsidence make the assumption in- 
valid. Consequently, local and remote sources must be separately treated by means of different filtering procedures. This may also allow for a specific and more detailed parameterization of the near-field sources, to which the local hazard is known to be more sensitive.

We tested the procedure by investigating a case study, i.e., Milazzo (Sicily). The work only has illustrative purposes and is not intended as a real hazard assessment at that site, due to some simplifications in the adopted model.

The new implemented filtering procedure allows for a consistent reduction of the number of tsunami inundation simulations and therefore of the computational cost of the analysis. It is worth stressing that in this specific application the computational efficiency was artificially enhanced by limiting the source variability, as well as by imposing high filter thresholds. In fact, a real assessment is expected to deal with a greater number of scenarios, provided that a finer tuning of the threshold values is carried out. This may in particular affect the computational cost related to the analysis of the near-field sources, for example when using stochastic slip distributions.

The most striking result is that the separate treatment of near-field sources provides significantly different and physically more consistent results with respect to the "uncorrected" procedure, showing that near-field sources must be specifically dealt with when evaluating site-specific SPTHA. We recall that the two approaches (with or without the correction for near-field) only differ in the way local sources are treated. Hence, the different results do not depend on the specific filtering thresholds but only on the coseismic deformation induced by local sources, which, if properly accounted for, modifies the effective tsunami hazard. Actually, for the specific configuration of this use case, our findings reveal that not considering an appropriate correction for near-field would lead to an overestimation of the tsunami hazard for $H_{\text {max }}$ greater than $1 \mathrm{~m}$, and this overestimation is correlated to dominant coastal uplift. However, different cases in terms of overestimation and underestimation may occur at different sites, depending on the relative source-site configuration. We also observe that Milazzo is located in an area featuring relatively low near-field tsunamigenic seismicity with respect to other areas in the Mediterranean Sea. Nevertheless, the method turns out to be sensitive even to relatively low displacements and allows for the detection and removal of significant biases from near-field sources.

The proposed method is suitable to be applied to operational assessments and also for improving local (multihazard) risk analyses (e.g., Goda and De Risi, 2018). We stress again that the approach developed here allows for the consideration of a very high number of tsunami scenarios, which is necessary to sufficiently explore the natural variability of the tsunami sources and the eventual alternative models needed for quantifying epistemic uncertainty.
Future work will be devoted to the use of the procedure to perform real local hazard assessments, exploiting the regional hazard retrieved from the TSUMAPS-NEAM project.

Data availability. The bathymetric data used for tsunami modeling are in the public domain and referenced in the text.

The regional hazard data are taken from Selva et al. (2016), as referenced in the text.

Hazard results are available upon request to the first author.

Supplement. The supplement related to this article is available online at: https://doi.org/10.5194/nhess-19-455-2019-supplement.

Author contributions. MV, SL and JS elaborated the method and analysed the results; MV performed the analysis, included numerical simulations, and prepared the figures; MV and SL wrote the manuscript; RT and JS reprocessed data from regional hazard; FR gave support in preparing the numerical simulations and analyzing results; $\mathrm{BB}$ produced the bathymetric grids; all authors reviewed the manuscript.

Competing interests. The authors declare that they have no conflict of interest.

Acknowledgements. The authors want to thank the EDANYA Research Group at the University of Malaga for providing the Tsunami-HySEA code for tsunami simulations. We acknowledge useful discussions with William Power and Gareth Davies during the early stages of this work. We also acknowledge constructive comments by four anonymous referees, which allowed for significant improvement of this paper. The work was partially funded by the INGV-DPC Agreement (Annex B2) and by the STREST project, EC Seventh Framework Programme (FP7/20072013), grant agreement no. 603389. All of the figures were created using either MATLAB (https://www.mathworks.com/, last access: 28 February 2019) or Generic Mapping Tools (http://gmt.soest.hawaii.edu, last access: 28 February 2019).

Edited by: Maria Ana Baptista

Reviewed by: four anonymous referees

\section{References}

Basili, R., Tiberti, M. M., Kastelic, V., Romano, F., Piatanesi, A., Selva, J., and Lorito, S.: Integrating geologic fault data into tsunami hazard studies, Nat. Hazards Earth Syst. Sci., 13, 10251050, https://doi.org/10.5194/nhess-13-1025-2013, 2013.

Bazzurro, P. and Cornell, C.: Disaggregation of seismic hazard, B. Seismol. Soc. Am., 89, 501-520, 1999.

Borrero, J. C., Lynett, P. J., and Kalligeris, N.: Tsunami currents in ports, Philos. T. Roy. Soc. A, 373, 20140372, https://doi.org/10.1098/rsta.2014.0372, 2015. 
Brizuela, B., Armigliato, A., and Tinti, S.: Assessment of tsunami hazards for the Central American Pacific coast from southern Mexico to northern Peru, Nat. Hazards Earth Syst. Sci., 14, 1889-1903, https://doi.org/10.5194/nhess-14-1889-2014, 2014.

Burbidge, D., Cummins, P. R., Mleczko, R., and Thio, H. K.: A Probabilistic Tsunami Hazard Assessment for Western Australia, Pure Appl. Geophys., 165, 2059-2088, https://doi.org/10.1007/s00024-008-0421-x, 2008.

Chock, G., Yu, G., Thio, H. K., and Lynett, P. J.: Target Structural Reliability Analysis for Tsunami Hydrodynamic Loads of the ASCE 7 Standard, J. Struct. Eng., 142, 04016092, https://doi.org/10.1061/(ASCE)ST.1943-541X.0001499, 2016.

Davies, G., Horspool, N., and Miller, V.: Tsunami inundation from heterogeneous earthquake slip distributions: Evaluation of synthetic source models, J. Geophys. Res.-Sol. Ea., 120, 6431-6451, https://doi.org/10.1002/2015JB012272, 2015.

Davies, G., Griffin, J., Løvholt, F., Glimsdal, S., Harbitz, C., Thio, H. K., Lorito, S., Basili, R., Selva, J., Geist, E., and Baptista, M. A.: A global probabilistic tsunami hazard assessment from earthquake sources, Geol. Soc. Spec. Publ., 456, 219, https://doi.org/10.1144/SP456.5, 2017.

de la Asunción, M., Castro, M. J., Fernández-Nieto, E., Mantas, J. M., Acosta, S. O., and González-Vida, J. M.: Efficient GPU implementation of a two waves TVD-WAF method for the two-dimensional one layer shallow water system on structured meshes, selected contributions of the 23rd International Conference on Parallel Fluid Dynamics ParCFD2011, Comput. Fluids, 80, 441-452, https://doi.org/10.1016/j.compfluid.2012.01.012, 2013.

Gailler, A., Calais, E., Hébert, H., Roy, C., and Okal, E.: Tsunami scenarios and hazard assessment along the northern coast of Haiti, Geophys. J. Int., 203, 2287-2302, https://doi.org/10.1093/gji/ggv428, 2015.

Geist, E. L.: Complex earthquake rupture and local tsunamis, J. Geophys. Res.-Sol. Ea., 107, ESE2-1-ESE2-15, https://doi.org/10.1029/2000JB000139, 2002.

Geist, E. L. and Lynett, P. J.: Source Processes for the Probabilistic Assessment of Tsunami Hazards, Oceanography, 27, 86-93, https://doi.org/10.5670/oceanog.2014.43, 2014.

Geist, E. L. and Oglesby, D. D.: Tsunamis: Stochastic Models of Occurrence and Generation Mechanisms, 1-29, Springer New York, New York, NY, USA, https://doi.org/10.1007/978-3-64227737-5_595-1, 2014.

Geist, E. L. and Parsons, T.: Probabilistic analysis of tsunami hazards, Nat. Hazards, 37, 277-314, https://doi.org/10.1007/s11069005-4646-z, 2006.

Goda, K. and De Risi, R.: Multi-hazard loss estimation for shaking and tsunami using stochastic rupture sources, Int. J. Disast. Risk Re., 28, 539-554, https://doi.org/10.1016/j.ijdrr.2018.01.002, 2018.

González, F. I., Geist, E. L., Jaffe, B., Kanoglu, U., Mofjeld, H., Synolakis, C. E., Titov, V. V., Areas, D., Bellomo, D., Carlton, D., Horning, T., Johnson, J., Newman, J., Parsons, T., Peters, R., Peterson, C., Priest, G., Venturato, A., Weber, J., Wong, F., and Yalciner, A.: Probabilistic tsunami hazard assessment at Seaside, Oregon, for near-and far-field seismic sources, J. Geophys. Res.Sol. Ea., 114, C11023, https://doi.org/10.1029/2008JC005132, 2009.
Grezio, A., Babeyko, A., Baptista, M. A., Behrens, J., Costa, A., Davies, G., Geist, E. L., Glimsdal, S., González, F. I., Griffin, J., Harbitz, C. B., LeVeque, R. J., Lorito, S., Løvholt, F., Omira, R., Mueller, C., Paris, R., Parsons, T., Polet, J., Power, W., Selva, J., Sørensen, M. B., and Thio, H. K.: Probabilistic Tsunami Hazard Analysis (PTHA): multiple sources and global applications, Rev. Geophys., 55, 1158-1198, https://doi.org/10.1002/2017RG000579, 2017.

Griffin, J. D., Pranantyo, I. R., Kongko, W., Haunan, A., Robiana, R., Miller, V., Davies, G., Horspool, N., Maemunah, I., Widjaja, W. B., Natawidjaja, D. H., and Latief, H.: Assessing tsunami hazard using heterogeneous slip models in the Mentawai Islands, Indonesia, Geol. Soc. Spec. Publ., 441, 4770, https://doi.org/10.1144/SP441.3, 2017.

Gusman, A. R., Tanioka, Y., MacInnes, B. T., and Tsushima, H.: A methodology for near-field tsunami inundation forecasting: Application to the 2011 Tohoku tsunami, J. Geophys. Res.-Sol. Ea., 119, 8186-8206, https://doi.org/10.1002/2014JB010958, 2014.

Harbitz, C., Glimsdal, S., Bazin, S., Zamora, N., Løvholt, F., Bungum, H., Smebye, H., Gauer, P., and Kjekstad, O.: Tsunami hazard in the Caribbean: Regional exposure derived from credible worst case scenarios, Cont. Shelf. Res., 38, 1-23, https://doi.org/10.1016/j.csr.2012.02.006, 2012.

Hoechner, A., Babeyko, A. Y., and Zamora, N.: Probabilistic tsunami hazard assessment for the Makran region with focus on maximum magnitude assumption, Nat. Hazards Earth Syst. Sci., 16, 1339-1350, https://doi.org/10.5194/nhess-161339-2016, 2016.

Horspool, N., Pranantyo, I., Griffin, J., Latief, H., Natawidjaja, D. H., Kongko, W., Cipta, A., Bustaman, B., Anugrah, S. D., and Thio, H. K.: A probabilistic tsunami hazard assessment for Indonesia, Nat. Hazards Earth Syst. Sci., 14, 3105-3122, https://doi.org/10.5194/nhess-14-3105-2014, 2014.

Kajiura, K.: The leading wave of a tsunami, B. Earthq. Res. I., 41, 535-571, 1963.

Kaufman, L. and Rousseeuw, P. J.: Finding Groups in Data: An Introduction to Cluster Analysis, John Wiley \& Sons, Inc., Hoboken, New Jersey, 2009.

Lay, T.: The surge of great earthquakes from 2004 to 2014, Earth Planet. Sc. Lett., 409, 133-146, https://doi.org/10.1016/j.epsl.2014.10.047, 2015.

LeVeque, R., Waagan, K., González, F., Rim, D., and Lin, G.: Generating random earthquake events for probabilistic tsunami hazard assessment, Pure Appl. Geophys., 173, 3671-3692, https://doi.org/10.1007/s00024-016-1357-1, 2016.

Li, L., Switzer, A. D., Chan, C.-H., Wang, Y., Weiss, R., and Qiu, Q.: How heterogeneous coseismic slip affects regional probabilistic tsunami hazard assessment: A case study in the South China Sea, J. Geophys. Res.-Sol. Ea., 121, 6250-6272, https://doi.org/10.1002/2016JB013111, 2016.

Lin, I. and Tung, C.: A preliminary investigation of tsunami hazard, B. Seismol. Soc. Am., 72, 2323-2337, 1982.

Lorito, S., Tiberti, M. M., Basili, R., Piatanesi, A., and Valensise, G.: Earthquake-generated tsunamis in the Mediterranean Sea: Scenarios of potential threats to Southern Italy, J. Geophys. Res.Sol. Ea., 113, B01301, https://doi.org/10.1029/2007JB004943, 2008.

Lorito, S., Piatanesi, A., Cannelli, V., Romano, F., and Melini, D.: Kinematics and source zone properties of the 2004 Sumatra- 
Andaman earthquake and tsunami: Nonlinear joint inversion of tide gauge, satellite altimetry, and GPS data, J. Geophys. Res.Sol. Ea., 115, B02304, https://doi.org/10.1029/2008JB005974, 2010.

Lorito, S., Selva, J., Basili, R., Romano, F., Tiberti, M. M., and Piatanesi, A.: Probabilistic Hazard for Seismically-Induced Tsunamis: Accuracy and Feasibility of Inundation Maps, Geophys. J. Int., 200, 574-588, https://doi.org/10.1093/gji/ggu408, 2015.

Lorito, S., Romano, F., and Lay, T.: Tsunamigenic Major and Great Earthquakes (2004-2013): Source Processes Inverted from Seismic, Geodetic, and Sea-Level Data, in: Encyclopedia of Complexity and Systems Science, edited by: Meyers, R. A., 1-52, Springer Berlin Heidelberg, Berlin, Heidelberg, https://doi.org/10.1007/978-3-642-27737-5_641-1, 2016.

Løvholt, F., Bungum, H., Harbitz, C. B., Glimsdal, S., Lindholm, C. D., and Pedersen, G.: Earthquake related tsunami hazard along the western coast of Thailand, Nat. Hazards Earth Syst. Sci., 6, 979-997, https://doi.org/10.5194/nhess-6-979-2006, 2006.

Løvholt, F., Glimsdal, S., Harbitz, C. B., Zamora, N., Nadim, F., Peduzzi, P., Dao, H., and Smebye, H.: Tsunami hazard and exposure on the global scale, Earth-Sci. Rev., 110, 58-73, https://doi.org/10.1016/j.earscirev.2011.10.002, 2012a.

Løvholt, F., Pedersen, G., Bazin, S., Kühn, D., Bredesen, R. E., and Harbitz, C.: Stochastic analysis of tsunami runup due to heterogeneous coseismic slip and dispersion, J. Geophys. Res.-Oceans, 117, C03047, https://doi.org/10.1029/2011JC007616, 2012b.

Løvholt, F., Davies, G., Griffin, J., Lorito, S., Volpe, M., Romano, F., Galvez, M. S., Geist, E., Ross, S., Ayrebe, I. A., Fraser, S., Thio, H. K., Canals, M., Gonzalez, F., Polet, J., Mokhtari, M., Kanoglu, U., Paris, R., Andrade, C., Baptista, M. A., Latief, H., and Papadopoulos, G.: Tsunami Hazard and Risk Assessment, in: Words into Action guidelines: National disaster risk assessment, Hazard Specific Risk Assessment, chap. 2, United Nations Office for Disaster Risk Reduction (UNISDR), Geneva, 2017.

Lynett, P., Wei, Y., and Arcas, D.: Tsunami Hazard Assessment: Best Modeling Practices and State-of-the-Art Technology, Nureg/cr-7223, U.S. Nuclear Regulatory Commission, Washington, DC, 2016.

Macías, J., Mercado, A., Gonzalez-Vida, J. M., Ortega, S., and Castro, M.: Comparison and Computational Performance of Tsunami-HySEA and MOST Models for LANTEX 2013 Scenario: Impact Assessment on Puerto Rico Coasts, Pure Appl. Geophys., 173, 3973-3997, https://doi.org/10.1007/s00024-0161387-8, 2016.

Macías, J., Castro, M. J., Ortega, S., Escalante, C., and GonzálezVida, J. M.: Performance Benchmarking of Tsunami-HySEA Model for NTHMP's Inundation Mapping Activities, Pure Appl. Geophys., 174, 3147-3183, https://doi.org/10.1007/s00024-0171583-1, 2017.

Marzocchi, W., Taroni, M., and Selva, J.: Accounting for epistemic uncertainty in PSHA: Logic Tree and ensemble modeling, B. Seismol. Soc. Am., 105, 2151-2159, https://doi.org/10.1785/0120140131, 2015.

Meade, B. J.: Algorithms for the calculation of exact displacements, strains, and stresses for triangular dislocation elements in a uniform elastic half space, Comput. Geosci., 33, 1064-1075, https://doi.org/10.1016/j.cageo.2006.12.003, 2007.
Molinari, I., Tonini, R., Lorito, S., Piatanesi, A., Romano, F., Melini, D., Hoechner, A., González Vida, J. M., Maciás, J., Castro, M. J., and de la Asunción, M.: Fast evaluation of tsunami scenarios: uncertainty assessment for a Mediterranean Sea database, Nat. Hazards Earth Syst. Sci., 16, 2593-2602, https://doi.org/10.5194/nhess-16-2593-2016, 2016.

Mueller, C., Power, W., Fraser, S., and Wang, X.: Effects of rupture complexity on local tsunami inundation: Implications for probabilistic tsunami hazard assessment by example, J. Geophys. Res.Sol. Ea., 120, 488-502, https://doi.org/10.1002/2014JB011301, 2014.

Murphy, S., Scala, A., Herrero, A., Lorito, S., Festa, G., Trasatti, E., Tonini, R., Romano, F., Molinari, I., and Nielsen, S.: Shallow slip amplification and enhanced tsunami hazard unravelled by dynamic simulations of mega-thrust earthquakes, Sci. Rep., 6, 35007, https://doi.org/10.1038/srep35007, 2016.

Okada, Y.: Surface deformation due to shear and tensile faults in a half-space, B. Seismol. Soc. Am., 75, 1135-1154, 1985.

Park, H. S. and Jun, C. H.: A simple and fast algorithm for K-medoids clustering, Expert Syst. Appl., 36, 3336-3341, https://doi.org/10.1016/j.eswa.2008.01.039, 2009.

Power, W., Wang, X., Wallace, L., Clark, K., and Mueller, C.: The New Zealand Probabilistic Tsunami Hazard Model: development and implementation of a methodology for estimating tsunami hazard nationwide, Geol. Soc. Spec. Publ., 456, 199, https://doi.org/10.1144/SP456.6, 2017.

Rikitake, B. T. and Aida, I.: Tsunami hazard probability in Japan, B. Seismol. Soc. Am., 78, 126-1278, 1988.

Romano, F., Piatanesi, A., Lorito, S., and Hirata, K.: Slip distribution of the 2003 Tokachi-oki $\mathrm{M}_{\mathrm{W}} 8.1$ earthquake from joint inversion of tsunami waveforms and geodetic data, J. Geophys. Res.Sol. Ea., 115, B11313, https://doi.org/10.1029/2009JB006665, 2010.

Satake, K., Fujii, Y., Harada, T., and Namegaya, Y.: Time and Space Distribution of Coseismic Slip of the 2011 Tohoku Earthquake as Inferred from Tsunami Waveform DataTime and Space Distribution of Coseismic Slip of the 2011 Tohoku Earthquake, B. Seismol. Soc. Am., 103, 1473-1492, https://doi.org/10.1785/0120120122, 2013.

Selva, J., Tonini, R., Molinari, I., Tiberti, M. M., Romano, F., Grezio, A., Melini, D., Piatanesi, A., Basili, R., and Lorito, S.: Quantification of source uncertainties in Seismic Probabilistic Tsunami Hazard Analysis (SPTHA), Geophys. J. Int., 205, 1780-1803, https://doi.org/10.1093/gji/ggw107, 2016.

Sepúlveda, I., Liu, P. L., Grigoriu, M., and Pritchard, M.: Tsunami hazard assessments with consideration of uncertain earthquake slip distribution and location, J. Geophys. Res.-Sol. Ea., 122, 7252-7271, https://doi.org/10.1002/2017JB014430, 2017.

Synolakis, C. and Kânoğlu, U.: The Fukushima accident was preventable, Philos. T. Roy. Soc. A, 373, 20140379 , https://doi.org/10.1098/rsta.2014.0379, 2015.

Tarquini, S., Isola, I., Favalli, M., Mazzarini, F., Bisson, M., Pareschi, M. T., and Boschi, E.: TINITALY/01: a new Triangular Irregular Network of Italy, Ann. Geophys., 50, 407-425, https://doi.org/10.4401/ag-4424, 2007.

Tarquini, S., Vinci, S., Favalli, M., Doumaz, F., Fornaciai, A., and Nannipieri, L.: Release of a 10-m-resolution DEM for the Italian territory: Comparison with global-coverage DEMs and 
anaglyph-mode exploration via the web, Comput. Geosci., 38, 168-170, https://doi.org/10.1016/j.cageo.2011.04.018, 2012.

Thio, H. K., Somerville, P. G., and Polet, J.: Probabilistic Tsunami Hazard in California, PEER Report 2010/108, Pacific Earthquake Engineering Research Center, College of Engineering, University of California, Berkeley, 2010.

Tinti, S. and Armigliato, A.: The use of scenarios to evaluate tsunami impact in southern Italy, Mar. Geol., 199, 221-243, 2003.
Tonini, R., Armigliato, A., Pagnoni, G., Zaniboni, F., and Tinti, S.: Tsunami hazard for the city of Catania, eastern Sicily, Italy, assessed by means of Worst-case Credible Tsunami Scenario Analysis (WCTSA), Nat. Hazards Earth Syst. Sci., 11, 1217-1232, https://doi.org/10.5194/nhess-11-1217-2011, 2011. 